\title{
O PONTO DE VISTA DE PAIS E PROFESSORES A RESPEITO DAS INTERAÇÕES LINGUÍSTICAS DE CRIANÇAS SURDAS ${ }^{1}$ \\ PARENTS' AND TEACHERS' POINTS OF VIEW ABOUT DEAF CHILDREN'S LINGUISTIC INTERACTIONS
}

\author{
Simone SCHEMBERG ${ }^{2}$ \\ Ana Cristina GUARINELLO ${ }^{3}$ \\ Giselle MASSI ${ }^{4}$
}

\begin{abstract}
RESUMO: diversos estudos atuais têm revelado que a surdez deve ser reconhecida como diferença, especialmente no que diz respeito aos aspectos linguístico-discursivos. Contudo, crianças surdas vêm enfrentando, na família e na escola, barreiras linguísticas com implicações nas suas possibilidades de inclusão social. Nessa direção, o presente trabalho objetiva analisar o ponto de vista de pais e professores a respeito das interações linguísticas de crianças surdas no âmbito familiar e escolar, considerando o contexto da inclusão. Foram entrevistados doze familiares (quatro pais e oito mães) de crianças surdas que frequentam o ensino regular e foi aplicado um questionário junto a doze professores dessas mesmas crianças. Os resultados apontam que nem os familiares nem os professores usam a língua de sinais para interagir com os surdos, gerando interações linguísticas restritas e pouco efetivas. Além disso, percebeu-se que familiares e professores apresentam um desconhecimento acerca da surdez, da língua de sinais e das consequências da surdez para o surdo.
\end{abstract}

PALAVRAS-CHAVE: Educação Especial. Inclusão. Surdos. Família. Língua de Sinais.

\begin{abstract}
Several studies argue that deafness should be currently considered as a difference, specifically regarding linguistic discursive aspects. Nevertheless, at home and at school deaf children have to face linguistic barriers that affect their social inclusion. This study aims to analyze points of view of parents and teachers related to the deaf child's linguistic interactions at home and at school, considering the context of inclusion. Twelve parents (four fathers and eight mothers) of deaf children enrolled in regular schools were interviewed and a questionnaire was applied to these children's twelve teachers. The results show that neither parents nor teachers use sign language to interact with these children and that there linguistic interactions were restricted and not very effective. Furthermore, the answers by parents and teachers demonstrate a lack of understanding about deafness, sign language and its consequences upon the deaf individual.
\end{abstract}

KEYWORDS: Special Education. Inclusion. Deaf people. Family. Sign language.

\section{INTRODUÇão}

Diante do atual contexto educacional, especificamente no caso dos alunos surdos, a inclusão tem se processado em meio a divergências e desafios que vão além da superação de barreiras físicas e adaptações curriculares. As questões

\footnotetext{
${ }^{1}$ O presente trabalho faz parte da Dissertação de Mestrado intitulada: "Surdez, Inclusão e Letramento: o lugar concebido ao surdo nos contextos familiar e escolar" defendida pela Mestre Simone Schemberg em 2008.

${ }^{2}$ Mestre em Distúrbios da Comunicação, Universidade Tuiuti do Paraná. simoneschemberg@hotmail.com

${ }^{3}$ Doutora em Linguística pela UFPR, Docente do Programa do Mestrado e Doutorado em Distúrbios da Comunicação e do Curso de Graduação em Fonoaudiologia da Universidade Tuiuti do Paraná. ana.guarinello@utp.br

${ }^{4}$ Doutora em Linguística pela UFPR, Docente do Programa do Mestrado e Doutorado em Distúrbios da Comunicação e do Curso de Graduação em Fonoaudiologia da Universidade Tuiuti do Paraná. giselle.massi@utp.br
} 
relacionadas às barreiras linguístico-discursivas com que estes alunos se deparam, tanto na família quanto na escola, trazem à tona implicações e imposições que demandam mudanças atitudinais e conceptuais quanto ao sujeito surdo e suas possibilidades de fazer uso da linguagem em diferentes situações sociais. Os atuais discursos em relação à surdez traduzem questões que retratam a necessidade de reconhecê-la enquanto diferença a ser considerada, sobretudo, no que diz respeito aos aspectos linguístico-discursivos.

Diante disso, alguns documentos destacam a relevância de se levar em conta os diferenciais linguísticos no processo educacional dos surdos, como a Declaração de Salamanca (BRASIL, 1994), que ressalta o dever, por parte das políticas educativas, de considerar as diferenças individuais, destacando a importância de se assegurar a língua de sinais a todos os surdos. Em consonância com os princípios políticos e filosóficos que a permearam, a Resolução $\mathrm{N}^{\circ} .2$ de 11 de setembro de 2001 (BRASIL, 2001) que institui as Diretrizes Nacionais para Educação Especial na Educação Básica, também destaca a importância da língua de sinais no acesso aos conteúdos curriculares, ao afirmar que: "Em face das condições específicas associadas à surdez, é importante que os sistemas de ensino se organizem de forma que haja escolas em condições de oferecer aos alunos surdos o ensino em Língua Brasileira de Sinais e em Língua Portuguesa [...]” (p. 45).

As novas posturas frente à surdez, considerando a diferença linguística, abrem caminho a outras determinações legais que fortalecem o reconhecimento da língua de sinais em âmbito nacional. A Lei Federal 10.436, de 24 de abril de 2002 (BRASIL, 2002), reconhece a Língua Brasileira de Sinais (LIBRAS) no país, afirmando que o apoio ao uso e a difusão da mesma sejam garantidos por parte do poder público em geral e das empresas concessionárias de serviços públicos. Em detrimento da urgência em se estabelecer políticas significativas com relação ao reconhecimento da diferença linguística, é estabelecida, ainda, a partir do decreto 5.626 de 22 de dezembro de 2005 (BRASIL, 2005), a garantia a uma educação bilíngue, diante da qual se reconhece a importância da precocidade da língua de sinais na vida social do surdo, destacando a necessidade da presença do tradutor e intérprete nas instituições de ensino, bem como a do instrutor de língua de sinais. Além disso, é proposta a inserção da Libras como disciplina curricular em diversos cursos de formação em diferentes áreas do conhecimento.

No entanto, há de se considerar que outras questões urgem em se estabelecer no que diz respeito à consideração da diferença, no caso da surdez. Considerações estas que se estabelecem tanto no contexto familiar, quanto no contexto escolar e que vão além das especificações legais e do cumprimento das leis. A família e a escola representam os dois principais ambientes de desenvolvimento humano nas sociedades contemporâneas, em vista disso, é fundamental que sejam implementadas políticas que possibilitem a aproximação desses dois contextos, sobretudo no que se refere aos processos de desenvolvimento e aprendizagem (DESSEN; POLONIA, 2007). 
No caso das crianças surdas, a escola pode assegurar o desenvolvimento da língua de sinais, que assim como outras línguas, passa por um processo de aquisição, por meio do qual os conceitos e o conhecimento de mundo são construídos. Dessa forma, o acesso precoce a mesma é determinante para a constituição do sujeito surdo. Diferentemente da criança ouvinte, que desde cedo têm contato com a linguagem oral, a criança surda está inserida num contexto no qual as interações linguísticas não são compartilhadas, considerando que 95\% são filhas de pais ouvintes, os quais, em geral, desconhecem ou rejeitam a língua de sinais (SKLIAR, 1997). A falta de contato com adultos que compartilhem de uma mesma língua pode significar uma desvantagem no desenvolvimento educacional da criança surda (QUADROS; CRUZ, 2011).

Em se tratando de familiares ouvintes com filhos surdos, geralmente, são os pais que escolhem a primeira forma de comunicação para os filhos, pois são eles que irão dispor de recursos, tempo, investimento, aulas, tratamentos e colégios para alcançar seus objetivos (SANTANA, 2007). Dessa forma, a formação subjetiva desse filho surdo depende de uma série de fatores como: sua opção pessoal de comunicação, escolha da comunicação pela família, ambiente social, educação, entre outros.

Sabe-se que a língua oral é de modalidade oral-auditiva diferente da língua de sinais, língua natural do surdo, de modalidade visual-espacial. Desse modo, uma primeira barreira pode começar a ser construída, pois, em muitos casos, não há uma língua comum entre a família e a criança surda para estabelecer os contatos sociais e assim permitir que a linguagem seja viva e fluente nas interações (GUARINELLO, 2007). De nada adianta que as leis falem da importância da educação bilíngue para os surdos, se as próprias famílias não utilizam a língua de sinais, ou seja, as famílias continuam a utilizar somente a língua oral, e usualmente, não estruturam nenhum código linguístico eficaz com seus filhos, o que acarreta prejuízos no desenvolvimento intelectual, afetivo, social e linguístico dessas crianças (RABELO, 2006).

Neste sentido, é importante destacar o papel da família, pois é através dela que o alicerce da personalidade subjetiva é construído, de forma que o desenvolvimento da criança é, em grande parte, de sua responsabilidade. Como pontua Schneider (2006): "A escola sozinha não pode dar conta da educação de todos e, particularmente, dos alunos surdos se não contar com a participação da família, pois, se quiser desenvolver uma educação emancipadora, deve-se considerar o mundo da vida da criança" (p. 176).

A interação familiar é de fundamental importância na constituição social do sujeito. A família é como afirma Guarinello (2000), o primeiro local onde as capacidades das crianças são desenvolvidas, ao mesmo tempo em que, como referem Negreli e Marcon (2006), é no espaço familiar que os valores e as crenças são transmitidos de geração em geração, de modo que o empreendimento conjunto entre criança e adulto é determinante. Diante dessas considerações, é importante destacar que o modo como a criança é tratada no contexto familiar terá grande influência sobre a imagem que terá de si mesma (STELLING, 1999). 
Em pesquisa realizada Schneider (2006), ao referir-se à visão de um grupo de pais de crianças surdas, constatou que apesar de os mesmos destacarem a importância da língua de sinais no processo escolar de seus filhos, demonstraram não fazer uso da mesma, o que se reflete em uma das principais dificuldades do surdo: a falta de referenciais para o desenvolvimento de um processo de identificação e aquisição da língua de sinais. Além disso, a autora pôde perceber, na narrativa dos pais, que há uma negação com relação às dificuldades enfrentadas pelos filhos no ensino regular. Ou seja, os pais não se ocupam das dificuldades apresentadas pelo filho surdo para acompanhar um ensino regular que, pautado na homogeneidade, desconsidera a língua de sinais, evidenciando a dificuldade dos próprios pais em reconhecer as especificidades desse filho.

Outras pesquisas, ainda (BORGES, 2004; SOARES; LACERDA, 2004; GUARINELLO et al, 2006) revelam uma série de dificuldades enfrentadas pelo aluno surdo no contexto de inclusão. Borges (2004) constatou, a partir de pesquisas realizadas com alunos surdos inseridos no ensino médio, que para eles a comunicação no ensino regular é restrita, o que reduz as possibilidades de interação e leva alguns surdos a darem preferência à escola especial, já que nesta as oportunidades de comunicação são maiores. No entanto, o reconhecimento da escola regular como mais adequada, é apontado na pesquisa por ser nesta que o surdo tem acesso aos conteúdos acadêmicos e a oportunidades que o favorecerão futuramente. Em concordância, Botelho (2002) refere que no ensino regular é oportunizado ao surdo um nível acadêmico mais elevado e melhores oportunidades de acesso ao currículo em relação às escolas especiais. Soares e Lacerda (2004) criticam o fato de o processo de ensino ser pensado tendo como base alunos ouvintes.

A partir de uma pesquisa realizada com um grupo de professores do Estado do Paraná, Guarinello et al (2006), retratam as dificuldades do aluno surdo em sala de aula no ensino regular, do ponto de vista dos professores. Tal pesquisa revelou que as maiores dificuldades do surdo dizem respeito, segundo os professores entrevistados, em maior percentual, à elaboração, compreensão e interpretação textual. Além disso, a interação, o despreparo dos professores e a falta de intérprete também foram apontados. O desconhecimento sobre a surdez e suas implicações também foi constatado, o que é um ponto fundamental no processo de ensino-aprendizagem, pois pode gerar atitudes e pré-conceitos que irão interferir nas interações, podendo suscitar discursos equivocados e de insatisfação com relação ao aluno e à surdez.

Diante de tais constatações acerca do processo educacional inclusivo do surdo é possível perceber que há uma carência no que diz respeito à real concretitude do respeito à diversidade. Torna-se necessário articular possibilidades de ensinoaprendizagem considerando efetivamente a diferença em todos os aspectos. Não basta apenas reconhecer a existência da diferença e do pluralismo cultural, mas oportunizar meios para a efetivação de educação bilíngue onde, assim como pontua Fernandes (2003), "todas as vozes tenham o seu lugar de valorização e reconhecimento" (p.39). 
Fernandes (2003), no entanto, nos chama a atenção para o fato de que "um programa de educação bilíngue não se sustenta apenas pela mera constatação da necessidade de um trabalho que envolva duas línguas no processo educacional" ( $p$. 40). Segundo a autora, há outras questões éticas e políticas que devem ser levadas em consideração no processo educacional dos surdos, as quais dizem respeito, em síntese, à aceitação dos surdos como grupo que constitui sua identidade linguística e cultural a partir de uma língua natural; ao reconhecimento político da língua de sinais; à superação da perspectiva terapêutica; ao reconhecimento da presença de adultos surdos no processo educacional; ao estabelecimento de políticas de formação docente e o domínio efetivo da língua de sinais por parte destes.

Acerca da língua de sinais, Schneider (2006) também defende que seja oferecido ao aluno surdo um ambiente que lhe propicie possibilidades de aquisição, desenvolvimento e uso da língua de sinais de forma natural e espontânea, sendo priorizadas, ainda, no âmbito do ensino regular condições que possam garantir uma escolarização com qualidade.

Diante das atuais discussões e pesquisas no campo da Educação de Surdos é possível perceber que a Proposta Bilíngue tem se mostrado como sendo a mais satisfatória e capaz de contemplar as necessidades linguísticas e sociais do surdo (FERNANDES, 2003; QUADROS, 2006; PEIXOTO, 2006). Porém, não basta somente definir leis e aceitar a inserção do aluno surdo em sala de aula, mas refletir sobre novas propostas e concepções que privilegiem o processo de ensino aprendizagem com vistas as suas diferenças e particularidades, possibilitando-lhe a compreensão dos conteúdos de modo significativo, inserindo-o verdadeiramente nos contextos linguísticos.

De fato, especificamente em âmbito nacional, algumas propostas já foram estabelecidas em documentos relacionados à educação inclusiva (BRASIL, 2000; BRASIL 2001; BRASIL, 2006), como adaptações curriculares e de acesso ao currículo. No entanto, na prática faz-se necessária uma mudança real, desde o projeto pedagógico da escola até os critérios de avaliação, já que estes foram, tradicionalmente, pensados a partir de uma visão homogênea de sala de aula, como se todos os alunos se desenvolvessem da mesma maneira e ao mesmo tempo, assim como em uma linha de montagem, como é apontado por Alves (2006) ao comparar o processo de escolarização a um processo de produção, onde cada peça deve seguir os moldes de uma peça padrão:

Nossas escolas são constituídas segundo o modelo das linhas de montagem. Escolas são fabricas organizadas para a produção de unidades biopsicológicas móveis, portadoras de conhecimento e habilidades. Esses conhecimentos e habilidades são definidos por agências governamentais a que se conferiu autoridade para isso. Os modelos estabelecidos por tais agências são obrigatórios e têm força de lei. Unidades biopsicológicas móveis que, ao final do processo, não estejam de acordo com tais modelos são descartadas. É sua igualdade que atesta a qualidade do processo. Não havendo passado no teste da qualidade-igualdade, elas não recebem os certificados de excelência ISSO-12.000, vulgarmente denominados diplomas. As unidades biopsicológicas móveis são aquilo que vulgarmente recebe o nome de 'alunos'. (p. 36). 
Nessa comparação o autor conduz a uma reflexão sobre os modelos estabelecidos na educação que, se analisados, tornam a inclusão um processo inviável diante de tal realidade, já que esta prevê que as diferenças sejam levadas em consideração, o que só é possível se o processo educacional for estruturado a partir de uma ótica na qual a heterogeneidade seja contemplada, desvinculando-se das propostas estabelecidas em outros tempos.

A partir dessas reflexões, o presente trabalho objetiva analisar o ponto de vista de pais e professores a respeito das interações linguísticas com crianças surdas no âmbito familiar e escolar, considerando o contexto da inclusão.

\section{Método}

Esta pesquisa está vinculada ao Núcleo de trabalho Surdez, Linguagem e Educação, o qual faz parte do Programa de Mestrado e Doutorado em Distúrbios da Comunicação da Universidade Tuiuti do Paraná. Foi aprovada pelo comitê de ética sob o número 1206.

A pesquisa foi desenvolvida sob a perspectiva da inclusão educacional, considerando a inserção de alunos surdos no ensino regular, os quais frequentam o Centro de Atendimento Especializado em Surdez (CAES), que está situado no espaço de uma escola regular de um município da região metropolitana de Curitiba- Pr/Brasil. Será enfocada a visão de pais e professores acerca da interação do filho/aluno surdo nas atividades familiares e escolares, de modo a desvendar a maneira que se estabelece a comunicação com o mesmo nestes contextos. Para isto foram selecionadas 12 crianças surdas inseridas no contexto do ensino regular. Convém esclarecer que o critério usado para selecioná-las refere-se ao fato de estarem matriculadas nos primeiros anos escolares. Após essa seleção foi realizada uma entrevista com seus pais (sendo quatro pais e oito mães) e outra entrevista com seus professores (ou seja, foi entrevistado o professor do ensino regular de cada criança surda). Assim, fazem parte do corpus dessa pesquisa quatro pais e oito mães, e doze professores. Ressalte-se que ao longo de nossa discussão, ao nos referirmos aos pais, estaremos utilizando pai e mãe, sendo numerados de acordo com seus filhos (mãe 1, mãe 2, pai 3 e assim por diante), da mesma forma o professor 1 corresponde a criança 1 e assim sucessivamente.

Com o grupo de pais foram desenvolvidas entrevistas semi-estruturadas a partir de quatro questões, aplicadas pessoalmente pela pesquisadora. Nas entrevistas foram enfatizados aspectos relacionados à visão dos pais acerca da interação com seus filhos surdos. Optou-se por utilizar o método da entrevista, o qual sob uma visão sócio-histórica tem a particularidade de ser compreendido como uma produção de linguagem, onde entrevistador e entrevistado estão dispostos numa situação de interação verbal em que os enunciados são constituídos numa relação dialógica (FREITAS, 2003).

Com relação ao grau de instrução os pais têm desde o ensino fundamental incompleto até o ensino médio completo. Cabe ressaltar que as famílias 
entrevistadas estão inseridas em um contexto de baixa renda. No que se refere ao meio de comunicação usado com os filhos surdos, apenas uma mãe faz uso de sinais e da oralidade ao mesmo tempo, todos os outros utilizam apenas a oralidade para se comunicar com seus filhos. Com relação ao conhecimento acerca da língua de sinais apenas uma mãe afirma que ter feito um curso de Libras.

Quanto aos docentes que compuseram a pesquisa, os 12 professores selecionados atuam no ensino fundamental $\left(1^{\circ}\right.$ a $5^{\circ}$ ano $)$, em diferentes escolas das redes municipal e estadual de ensino. Para a coleta de dados com os professores foram utilizados questionários com quatro questões fechadas e abertas, por ser este o instrumento mais conveniente, já que, na tentativa de entrevistas a serem realizadas in loco, alguns professores se mostraram indispostos e declararam não terem tempo. Os questionários lhes foram entregues e devolvidos à pesquisadora dois a três dias depois. No questionário foram enfocados aspectos referentes à interação com os alunos surdos no contexto da inclusão.

Com relação ao tempo de docência dos professores entrevistados é possível afirmar que eles têm entre cinco e vinte e três anos de docência. No que se refere a experiência anterior com alunos surdos, apenas um professor afirma que conta com tal experiência. Quanto a formação na área da surdez, quatro professores relataram que possuem essa formação.

A metodologia desta pesquisa é de cunho qualitativo, considerando que o significado humano da vida social e a sua elucidação e exposição pelo pesquisador é um aspecto importante na pesquisa (MOREIRA; CALEFFE, 2006). Analisar os dados qualitativamente é um ponto fundamental da presente pesquisa, considerando que tal abordagem, segundo Chizotti (1998), parte do principio de que há uma relação dinâmica entre o mundo real e o sujeito, um vínculo entre o mundo objetivo e a subjetividade. Sendo assim, como afirmam Bogdan e Biklen (1998 apud TURATO, 2000), o pesquisador tem como alvo principalmente “[...] melhor compreender o comportamento e a experiência humana. Eles procuram entender o processo pelo qual as pessoas constroem significados e descrevem o que são aqueles significados" (p. 95).

\section{Resultados E Discussão}

A fim de investigar como se estabelecem as relações com os filhos surdos em casa, as doze famílias foram questionadas: Como é a participação do filho nas atividades familiares?" , nas respostas foi possível perceber que, em geral, a criança surda tem pouca, ou nenhuma, participação nos contextos familiares, como é possível observar nos exemplos abaixo com episódios de falas dos pais:

Ela fica só na televisão, não tem participação, ela fica bem retirada (mãe 2).

Ele inventa muita 'arte'. É difícil conversar com ele, quase não conversa comigo e com o pai dele... (mãe 3).

Ele é 'triste', só pula o dia inteiro (mãe 12). 
Alguns pais relataram, ainda, a participação do filho referindo-se ao desempenho do mesmo nos trabalhos domésticos, como forma de demonstrar que há alguma participação:

Ele é um dos filhos que menos me dá trabalho. Ele me ajuda bastante. (mãe 7).

Ela gosta, já arruma a casa, varre a casa, ajuda bastante em casa. Ela tá sempre perguntando as coisas que não entende, e nós explicamos. (mãe 8).

Essas respostas vão de acordo com a literatura que refere as dificuldades que as famílias encontram para interagir e conversar com seus filhos surdos. De acordo com a literatura, a interação familiar é fundamental para a formação social do sujeito e também para a imagem do sujeito a respeito de si mesmo (STELLING, 1999; GUARINELLO, 2000). Assim como deve ser a imagem que esses sujeitos têm de si mesmos e dos seus papéis sociais na família. Se não participam efetivamente do contexto familiar, como uma criança pode se constituir na e pela linguagem?

Outro aspecto a ser considerado em torno da questão referente à participação da criança nas atividades familiares é que parece não haver uma compreensão sobre as implicações da surdez por parte dos pais, considerando os seguintes comentários:

Ela só não sabe contar o que aconteceu. Ela começa contar e não consegue falar. Participa dos assuntos olhando pra gente. (pai 1).

Ele é curioso. Ele 'ouve' quando quer. Às vezes fica nervoso. (mãe 4).

Ela entra no papo, tá sempre perguntando as coisas. Às vezes a gente tem que gritar com ela. (mãe 6).

Diante do comentário do pai 1 é possível perceber a pouca importância dada em relação à filha não conseguir narrar fatos (só não consegue contar), além disso, o "não conseguir falar" parece não estar relacionado, para o pai, à questão de que a filha não desenvolveu a fala naturalmente por não ouvir, e que, além disso, usa uma língua diferente da sua. O que nos leva a refletir que as interações linguísticas não são consideradas determinantes em tal contexto familiar, da mesma forma que não há um reconhecimento das implicações da surdez no sujeito: suas especificidades, suas possibilidades comunicativas, suas dificuldades para inserirse nos diversos contextos sociais.

Tais implicações podem, por exemplo, ser percebidas na fala da mãe 6 ao afirmar que "às vezes tem que gritar com a filha", como se ao gritar fosse haver melhor compreensão por parte da mesma, ou se dessa forma ela pudesse ouvir. Já no outro comentário, da mãe 4, a princípio somos levados a notar que há uma negação da surdez, ao referir-se que o filho só ouve quando quer, entretanto, se analisarmos melhor a mãe supostamente quis dizer que o filho somente presta atenção naquilo que lhe é interessante e conveniente. Além disso, se a criança é curiosa, somos levados a indagar se o 'ficar nervoso' não estaria 
então relacionado ao fato de suas curiosidades não serem correspondidas, o que consequentemente o deixaria nervoso.

Ora, se a família ouvinte continua interagindo com seus filhos por meio da língua oral, como é possível que essas crianças participem de maneira mais efetiva das situações familiares? As crianças não conseguem falar, mas é por meio dessa língua que a família espera que ela interaja, a criança não ouve e a mãe resolve gritar, a criança não entende, mas tem curiosidade para entender, enfim, todas essas questões ficam realmente muito complicadas diante de uma família que não partilha uma língua em comum. Vários autores referem que a língua de sinais é primordial para que as famílias consigam ter uma boa interação (SKLIAR, 1998; SCHNEIDER, 2006; SANTANA, 2007; GUARINELLO, 2007; QUADROS; CRUZ, 2011).

Apenas a mãe 5 e o pai 11 fizeram referência de que há participação constante do filho, sobretudo nas conversas do dia-a-dia:

Conversa até demais, até o que não é preciso. Ele participa de tudo, normal. (mãe $5)$.

Se deixar ela falar a gente não fala nada. Ela começou a participar mais ultimamente. Se desenvolveu bastante. Ela é bem ligada nos assuntos. (pai 11).

É fato que possa haver por trás dessas falas um desejo de evidenciar que o filho participa efetivamente dos contextos familiares. No entanto, em uma análise mais aprofundada é possível levantar uma reflexão em torno do modo com que os pais encaram a participação da criança, pois ao referir que a criança "fala até o que não é preciso", pode-se levantar a hipótese de que não é dada real importância ao que o filho fala, pelo fato de ser surdo e da imagem que se tem da surdez como sinônimo de impossibilidade.

De alguma forma, todos os pais colocaram sua visão a respeito da participação do filho em casa, referindo-se ao comportamento, a afazeres domésticos e à participação em conversas. É importante destacar aqui a forma como cada pai compreendeu essa questão, cada um percebe a participação do filho no contexto familiar sob um aspecto, alguns se referem à participação a partir da interação linguística, outros a partir da participação dos filhos em atividades domésticas e outros referem a pouca participação dos filhos de forma abrangente.

Ao serem questionados sobre como estabelecem a comunicação com o filho surdo, todos os pais apontaram que se comunicam por meio da fala. Dentre eles, apenas uma mãe afirmou fazer uso ocasional dos sinais. Além disso, ao serem questionados se já fizeram algum curso de língua de sinais, apenas uma das mães apontou que sim. Entretanto, ela não utiliza dessa língua para relacionar-se com o filho.

A supremacia da linguagem oral na concepção dos pais é percebida em seus depoimentos ao responderem que se comunicam só pela fala e não por gestos: "Normal, só pela fala" (mãe 2), "Normal. Conversando pela fala" (mãe 4) ou ainda: "Verbalmente, não por gestos" (mãe 12). Essa questão evidencia o 
que foi dito anteriormente a respeito da importância da família e da criança terem uma língua em comum (RABELO, 2006; GUARINELLO, 2007), ou seja, no caso de uma criança surda usuária de língua de sinais é fundamental que sua família partilhe essa língua. Se os pais só utilizam a fala para estabelecer algum tipo de comunicação com o filho, obviamente haverá pouca participação do mesmo, já que a criança não tem o domínio da linguagem oral, o que certamente fará com que se coloque numa posição isolada e, "retirada" dos contextos linguísticos que circulam no espaço familiar, conforme relato de uma mãe sujeito dessa pesquisa.

Convém considerarmos que não é a surdez responsável pela alienação da criança dos contextos familiares, mas a falta de possibilidades para que possa inserirse nos mesmos, pois "se a comunicação não pode ser obtida, se a criança não é exposta à língua e ao diálogo apropriados, verificamos todos os reveses [...] ao mesmo tempo linguísticos, intelectuais, emocionais e culturais." (SACKS, 1998, p. 130).

Portanto, a falta de participação do filho nas atividades familiares pode ser justificada pela falta de interação e de trocas dialógicas estabelecidas com esse filho. Dessa forma, parece-nos possível inferir que os pais não percebem que a pouca participação e interação do filho nos contextos familiares têm a ver com a questão de não possuírem uma língua em comum, que é uma das implicações da surdez. Contudo, é preciso que fique claro a eles que a surdez é responsável por tais situações, e os pais que prestarem atenção nisso poderão constituir espaços interativos mais efetivos com seus filhos no seio familiar (SKLIAR, 1998; GUARINELLO, 2007).

Ao analisar o modo com que se estabelece a comunicação com a criança surda no âmbito familiar, foi possível perceber, nas falas dos pais, que existe uma barreira linguística, que impede a criança, muitas vezes, de participar ativamente dos contextos linguísticos que circulam em casa. Tal barreira, entretanto, não se faz presente somente no contexto familiar. É sob esse aspecto que focalizamos a questão da inclusão escolar, tendo em vista que, neste contexto, tal barreira também se estabelece. Assim, considerar as vozes dos professores é de fundamental importância para que se possa perceber de que forma os mesmos interagem com seu aluno surdo e se este ocupa um lugar de sujeito ativo nos contextos linguísticodiscursivos de sala de aula. Sendo assim, foi apontado pelos professores, a partir dos questionários, o modo como são constituídas as interações linguísticas em sala de aula com o aluno surdo.

No que diz respeito à questão: "Como é estabelecida a comunicação com o aluno em sala de aula?", somente um professor apontou os gestos e a escrita, além da fala e da leitura labial. Outras duas professoras referiram a leitura labial, sendo que uma delas apontou somente a leitura labial. Os demais professores referiram que só se utilizam da fala, tal qual fazem com os alunos ouvintes.

Nesse ponto cabe fazer uma reflexão acerca da inclusão do aluno surdo no ensino regular, pois desde 1994 com a Declaração de Salamanca (BRASIL, 1994) e depois disso com várias resoluções e leis (BRASIL, 2000; 2001; 2002; 2005) já tem se discutido que os sistemas de ensino devem se organizar a fim de que as escolas 
possam oferecer a seus alunos uma educação bilíngue. Nesse sentido, a língua de sinais, os recursos visuais e outras formas de comunicação deveriam ser utilizados com esses alunos em sala de aula. Porém, nas respostas dadas pelos professores que participaram da pesquisa percebe-se que a maioria utiliza-se apenas da fala para se comunicar com seu aluno surdo. Ressalte-se que a questão não perguntava que língua o professor utiliza para dar aulas, mas sim como eles se comunicam com seus alunos surdos em sala de aula.

Acerca da leitura labial convém fazer um parêntese a respeito da falsa impressão que a mesma denota. As pessoas tendem a acreditar que os surdos, em grande parte, realizam leitura labial e consequentemente compreendem o que está sendo dito no seu entorno. Sobre isso, Botelho (1999) afirma que apenas 25\% do que se diz pode ser identificado, isto pelos melhores leitores labiais do mundo. A autora aponta que, apesar de a leitura labial ser útil algumas vezes, considerando a interação surdo-ouvinte, a mesma não garante a compreensão, pois depende da compreensão do contexto, da integração do conjunto de elementos verbais e não-verbais, da atitude ativa do sujeito na interação e da eliminação da simulação da compreensão.

Quando questionados sobre o conhecimento com relação à língua de sinais, a maioria referiu que considera insuficiente, pois apenas conhecem alguns sinais, mas têm dificuldades em utilizá-los. Três professores chegaram a afirmar que a desconhecem totalmente. Somente uma professora relatou conhecer a língua de sinais, o que se deve ao fato de ter uma filha surda. Entretanto, esta mesma professora, assim como as demais, não apontou a língua de sinais ao ser interrogada sobre a comunicação com o aluno, como analisado anteriormente.

Portanto, a partir da participação dos sujeitos dessa pesquisa é possível afirmar que há um considerável desconhecimento por parte de professores acerca do aluno surdo, da surdez e da língua de sinais. Conforme foi apontado na introdução desse trabalho, várias pesquisas demonstram que os professores desconhecem a surdez e a língua de sinais (BOTELHO, 2002; BORGES, 2004; SCHNEIDER, 2006; GUARINELLO et al, 2006), porém até quando os professores se manterão nessa posição passiva de desconhecimento, de falta do saber? Será que quando se recebe um aluno surdo não é possível verificar como trabalhar com ele, o que fazer, o que é língua de sinais?

No que diz respeito à formação para atuar com aluno surdo, apenas três professores possuem algum curso relacionado à Surdez. Acerca disso, levantamos uma reflexão em relação ao fato de que, ainda que o professor deva, por conta própria, buscar constantemente aprimorar-se no campo educacional, ao se propor a inclusão, nos contextos em questão, de um modo geral, não foram consideradas as determinações legais que privilegiam a formação do professor para poder atender à diversidade, tendo em vista a falta de programas de formação continuada. E mesmo que esses três professores possuam formação para atuar na surdez, os mesmos responderam que tem dificuldades para compreender as implicações da surdez e possuem pouco conhecimento a respeito da língua de sinais. 
No artigo 18 da Resolução 02/2001 (BRASIL, 2001) é estabelecido que os professores, para atuarem com alunos com necessidades especiais sejam capacitados e/ou especializados. Porém, a responsabilidade fica a cargo do professor, não sendo mencionado claramente a obrigatoriedade do município em ofertar cursos de formação, mencionando-se apenas que sejam oferecidas formações a professores em nível médio por instituições de ensino.

Lacerda (2006) refletindo sobre o processo de inclusão dos alunos surdos constatou que a inclusão apresenta-se como uma proposta adequada para a comunidade escolar, que se mostra disposta ao contato com as diferenças, porém não necessariamente satisfatória para aqueles que, tendo necessidades especiais, necessitam de uma série de condições que, na maioria dos casos, não têm sido propiciadas pela escola.

Em meio a esse contexto de dicotomias, entre o que se determina legalmente e o que efetivamente se concretiza nas escolas, está a criança surda, excluída constantemente das interações linguísticas, não compartilhando das trocas culturais constituídas historicamente. Concretizar de fato a inclusão não é tarefa fácil, entretanto, é uma realidade que urge em ser efetivada, pois o atual contexto social pressupõe a busca a equiparação dos direitos e o reconhecimento das diferenças. Sendo assim, torna-se fundamental que familiares e educadores reflitam sobre o papel determinante que desempenham para efetivar a inclusão de pessoas surdas na escola e na sociedade (SCHEMBERG, 2008).

\section{ConClusões}

A constante exclusão da criança surda das interações, tanto no contexto familiar quanto escolar, denota o desconhecimento acerca das questões ligadas à surdez e ao surdo por parte dos sujeitos envolvidos no processo de sua formação. A falta de uma participação efetiva de pessoas surdas nestes contextos se estabelece, sobretudo, por não haver um compartilhamento de uma língua em comum entre elas e os ouvintes. É preciso considerar que as interações por parte dos pais e professores, com seus filhos e alunos, respectivamente, se constituem a partir da modalidade oral-auditiva de linguagem, a qual, grande parcela dos surdos não tem acesso.

Interpolando família e escola é possível perceber que as dificuldades referentes às interações linguísticas se mostram como um fator a ser considerado. O desconhecimento acerca da surdez e da língua de sinais ocorre tanto na família, quanto na escola, pois familiares e professores, ao serem indagados sobre como consideram seu conhecimento em torno da surdez e da língua de sinais, referiram que consideram regular o seu conhecimento acerca da surdez, apresentando dificuldades em compreender as implicações relacionadas à mesma.

É fato que alguns aspectos já foram privilegiados no âmbito de propostas políticas, sobretudo a partir do decreto 5626/05 (BRASIL, 2005), entretanto, diante de nossa pesquisa frente às experiências de inclusão educacional do surdo, 
é possível perceber que os surdos não têm participação efetiva nas interações linguísticas que ocorrem tanto no âmbito familiar quanto no escolar. Isso, de acordo com as análises mostradas, deve-se ao fato de tanto a família quanto a escola usarem quase que unicamente a língua oral para se comunicar com um sujeito que se constituiu por uma língua viso-espacial.

Outro aspecto relevante é que os pais e professores afirmam desconhecimento acerca da surdez, da língua de sinais e das consequências da surdez para o surdo. Dessa forma, ressalta-se a necessidade de investir na promoção desse conhecimento, o qual é fundamental para que os surdos sejam inseridos em contextos linguístico-discursivos efetivos a partir de um diálogo entre família e escola. Aliadas, essas instituições podem proporcionar situações em que a vivacidade da linguagem se estabeleça levando em conta as diferenças e as especificidades de cada sujeito. Desse modo, cabe à escola alinhada à família, refletir sobre novas posturas a serem adotadas com relação à inserção do aluno surdo nos contextos linguístico-discursivos, considerando a perspectiva da inclusão.

\section{REFERÊNCIAS}

ALVES, R. A escola com que sempre sonhei sem imaginar que pudesse existir. 9. ed. São Paulo: Papirus, 2006.

BORGES, A. R. A inclusão de alunos surdos na escola regular. Espaço, Rio de Janeiro, v.21, p.63-68, 2004.

BOTELHO, P. Educação inclusiva para surdos: desmistificando pressupostos. In: SEMINÁRIO INTERNACIONAL SOCIEDADE INCLUSIVA, 1., 1999. Anais... PUC: Minas Gerais. Setembro, 1999. Disponível em: <http:/ / www.socidadeinclusiva. pucminas.br/anais.php>. Acesso em: 08 jun. 2008.

Linguagem e letramento na educação dos surdos - ideologias e práticas pedagógicas. Belo Horizonte: Autêntica, 2002.

BRASIL. Coordenadoria nacional para integração da pessoa portadora de deficiência. Declaração de Salamanca: sobre Princípios, Políticas e Práticas na área das Necessidades Educacionais Especiais. Brasília: CORDE, 1994.

.Projeto escola viva. Garantindo o acesso e permanência de todos os alunos na escola - Alunos com necessidades educacionais especiais. Secretaria de Educação Especial. Brasília: Mec, 2000.

.Diretrizes nacionais para a educação especial na educação básica. Res. CNE/CEB n.02/2001; Parecer CNE/CEB n. 017/2001.

.Lei Federal N. 10436 de 24 de abril de 2002: Dispõe sobre a Língua Brasileira de Sinais - Libras e dá outras providências. Brasília 2002. Disponível em: <http:/ /www. planalto.gov.br/ccivil/leis/2002/L10436.htm>. Acesso em: 20 abr. 2010.

.Decreto No 5626/2005: Regulamenta a Lei n ${ }^{\circ}$ 10436/2002, que dispõe sobre a Língua Brasileira de Sinais- LIBRAS, e o Art. 18 da Lei no 10098/2000. Brasília, 2005. 
BRASIL. Saberes e Práticas da Inclusão - Recomendações para a construção de escolas inclusivas. 2.ed. Brasília: MEC, Secretaria de Educação Especial, 2006.

CHIZOTTI, A. Pesquisa em ciências humanas e sociais. 3 ed. São Paulo: Cortez, 1998.

DESSEN, M. A.; POLONIA, A. C. Família e a Escola como contextos de desenvolvimento humano. Paidéia. Ribeirão Preto, v.17, n.36, p.21-32, 2007.

FERNANDES, S. Educação bilingüe para surdos: identidades, diferenças, contradições e mistérios. 2003. 216f. Tese (Doutorado em Estudos Linguísticos) - Setor de Ciências Humanas, Letras e Artes, Universidade Federal do Paraná, Curitiba.

FREITAS, M. T. A. A perspectiva sócio-histórica: uma visão humana da construção do conhecimento. In: FREITAS, M. T. A.; JOBIM e SOUZA, S.; KRAMER, S. (Org.) Ciências humanas e pesquisa - leituras de Mikhail Bakhtin. São Paulo: Cortez, 2003. p. 26-38.

GUARINELLO, A. C. A influência da família no contexto dos filhos surdos. Jornal Brasileiro de fonoaudiologia. Curitiba, n.3, p.28-33, 2000.

.O papel do outro na escrita de sujeitos surdos. São Paulo: Plexus, 2007.

GUARINELLO, A. C. et al. A inserção do aluno surdo no ensino regular: visão de um grupo de professores do Estado do Paraná. Revista Brasileira de Educação Especial, Marília, v.12, n.3, p.317-330, 2006.

LACERDA, C. B. F. A inclusão escolar de alunos surdos: o que dizem alunos, professores e intérpretes sobre esta experiência. Caderno CEDES, Campinas, v.26, n. 69, p.163-184, 2006.

MOREIRA, H.; CALEFFE, L. G. Metodologia da pesquisa para o professor pesquisador. Rio de Janeiro: DP\&A, 2006.

NEGRELI, M. E. D.; MARCON, S. S. Família e criança surda. Ciência, Cuidado e Saúde. Maringá, v.5, n.1, p.98-107, 2006.

PEIXOTO, R. C. Algumas considerações sobre a interface entre a língua brasileira de sinais (LIBRAS) e a língua portuguesa na construção inicial da escrita pela criança surda. Caderno CEDES. Campinas, n.69, p.205- 229, 2006.

QUADROS, R. M. Políticas lingüísticas: o impacto do decreto 5.626 para os surdos brasileiros. Espaço, Rio de Janeiro, n.25/26, p.19-25, 2006.

QUADROS, R. M.; CRUZ, C. R. Língua de sinais: instrumentos de avaliação. Porto Alegre: Artmed, 2011.

RABELO, A. S. Libras: aspectos lingüísticos e uso na terapia fonoaudiológica bilíngüe. Estudos, Goiânia, v.33, n.5/6, p.369-384, 2006.

SACKS, O. Vendo Vozes - uma jornada pelo mundo dos surdos. São Paulo: Companhia das Letras, 1998.

SANTANA, A. P. Surdez e Linguagem: aspectos e implicações neurolinguísticas. São Paulo: Plexus, 2007.

SCHEMBERG, S. Educação escolar e letramento de surdos: reflexões a partir da visão dos pais e professores. 2008, 184f. Dissertação (Mestrado em Distúrbios da Comunicação). Universidade Tuiuti do Paraná, Curitiba. 
SCHNEIDER, R. Educação de surdos - inclusão no ensino regular. Passo Fundo: Ed. Universitária de Passo Fundo, 2006.

SKLIAR, C. (Org.). Educação e exclusão: abordagens sócio-antropológicas em educação especial. 2. ed. Porto Alegre: Mediação, 1997.

.A Surdez: um olhar sobre as diferenças. Porto Alegre: Mediação, 1998.

SOARES, F. M. R; LACERDA, C. B. F. O aluno surdo em escola regular - um estudo de caso sobre a construção de identidade. In: GÓES, M. C. R.; LAPLANE, A. L. F. (Org.). Políticas e Práticas de Educação Inclusiva. Campinas: Autores Associados. 2004. p. 121-147.

STELLING, E. P. A relação da pessoa surda com sua família. Espaço. Rio de Janeiro, n.11, p. 45-47, 1999.

TURATO, E. R. Introdução à metodologia da pesquisa clínico-qualitativa - definição e principais características. Revista Portuguesa de Psicossomática. Sociedade Portuguesa de Psicossomática, Portugal, v.2, n.1, p.93-108, 2000.

Recebido em: 18/11/2010

Reformulado em: 24/06/2011

Aprovado em: 19/12/2012 
SCHEMBERG, S.; GUARINELLO, A. C.; MASSI, G. . 